\title{
Using Coupled Rheometer-FBRM to Study Rheological Properties and Microstructure of Cemented Paste Backfill
}

\author{
Hongjiang Wang $\mathbb{D}$, ${ }^{1}$ Liuhua Yang $\mathbb{D}^{1,2}$ Hong Li $\mathbb{D}^{1},{ }^{1}$ Xu Zhou $\mathbb{D}^{1},{ }^{1}$ and Xiaotian Wang $\mathbb{D}^{1}$ \\ ${ }^{1}$ School of Civil and Resource Engineering, University of Science and Technology Beijing, Beijing 100083, China \\ ${ }^{2}$ State Key Laboratory of Advanced Metallurgy, University of Science and Technology Beijing, Beijing 100083, China \\ Correspondence should be addressed to Liuhua Yang; yanglh2005@163.com
}

Received 20 March 2019; Revised 17 May 2019; Accepted 11 June 2019; Published 1 July 2019

Academic Editor: Luigi Nicolais

Copyright (c) 2019 Hongjiang Wang et al. This is an open access article distributed under the Creative Commons Attribution License, which permits unrestricted use, distribution, and reproduction in any medium, provided the original work is properly cited.

\begin{abstract}
Rheological properties, such as the yield stress, viscosity, and thixotropy, are related to the microstructure of cemented paste backfill (CPB). To highlight the relationship, two instruments were combined to measure the changes in the microstructure and the rheological properties of $\mathrm{CPB}$ simultaneously. In this way, the particle/agglomerate size distribution characterized by the focused beam reflectance measurement (FBRM) and the rheological factors measured by the rheometers could be directly linked. The results show that when under shearing, the intrinsic network structure of CPB responds to the shear-induced stresses with the interference of interparticle forces, leading to changes in the rheological behavior. Shear thinning can be found in CPB suspensions with a microstructure that is either loose interconnection or random. With an increase in the shear rate, random collisions among particles become organized in the flow, lowering the yield stress and viscosity. However, when the shear rate exceeds a certain threshold value, the rheological parameters change as a result of shear thickening. The results of this study contribute to better understanding of the complex rheological behavior of $\mathrm{CPB}$.
\end{abstract}

\section{Introduction}

During mining operations, a void is often created as a result of the removal of ores, which may cause some geotechnical problems [1]. In addition, only a small amount of the excavated rock or soil is used as valuable minerals [2]. The remaining rocks and tailings are considered as waste, and the waste contains abundant water. Therefore, a large amount of wastewater and tailings is discharged to the surface, and the most common tailings storage facility (TSF) is a tailings dam [3, 4]. Clearly, embankments have failed, and as it is, current construction will continue to fail. This may cause heavy metal pollution in soils and water [5]. The waste must be disposed of environmentally and in an economically acceptable manner. To solve these problems, the mining engineer proposed to use the cemented paste backfill (CPB) technology, which backfills the tailings with a certain amount of cementitious material that usually accounts for $2-10 \%$ of the total weight $[6,7]$. CPB technology excels in tailings utilization and the strength of filling body and is widely used in metal mines and coal mines $[8,9]$.

Although the CPB technology has some benefits, the costs and transportation of paste backfill are still a concern [10]. Typically, the CPB is prepared at a factory which is away from the stope and then piped to the underground goaf $[11,12]$. Therefore, whether it is transportable is the key to the success or the failure of this technology, and fluidity is often used to evaluate the transport performance of CPB $[13,14]$. Design of pipelines and prediction of pumping energy requirements rely on knowledge of the flow behavior of CPB. On the other hand, deterioration of fluidity will affect the paste performance and workability, hence resulting in subsequent structural defects [15]. Many scholars have developed various methods for measuring rheological properties of CPB $[16,17]$. Rheological tests have evolved into a very important discipline that both understands the transport properties of fluids and gives indirect feedback of fluid microstructure information [18]. Studies of Larson et al. showed that the rheometers will have 
a greater advantage if they could be combined with changes in the microstructure [19]. From a microstructural point of view, some rheological phenomena could be described as paste deflocculation and breakdown in the interparticle forces under shearing, and flocculation and formation of interparticle forces over at rest, such as thixotropy. However, understanding the initial fresh state microstructure of pastes is very difficult, and the difficulty in in situ monitoring of microstructures lies in the high concentration, hydration, low transmission, and vulnerability [20,21]. Therefore, most of the current understandings of the microstructure of the paste come from conjectures or limited experiments, especially when the sample is subject to shearing (i.e., mixing and pumping) [22].

The paddle rheometer test method is the most commonly used one in the paste rheology testing. A shear stressshear rate curve is obtained by the rheometer and then is fitted with the Bingham model or the Herschel-Bulkley model to obtain data, and yield stress and viscosity are often used to estimate the transportability or flowability of CPB [23]. However, this method does not solve the engineering practices well. When designing the required pump pressure, it often tends to be too large or too small, resulting in the waste of energy or pipeline blockages and shutdown. One of the reasons for this problem is that, with the rheometer test method, we do not know what changes the paste has undergone under shearing, so we cannot objectively explain some phenomena, such as shear thinning and shear thickening. Similarly, we do not know whether the experimental phenomenon found from the rheometer is caused by the paste itself or is it due to the error caused by the instrument or the method [24]. Simply stated, particles will aggregate/ disperse when attractive forces exceed or are less than the repulsive forces, and this contributes to the changes of rheological properties of the paste. Thus, to monitor the size changes of the particle disperse/aggregates is likely to be the most representative parameter for understanding the complex rheological properties of $\mathrm{CPB}$. In the latest research, scanning electron microscopy (SEM) has been used to observe the microstructure of CPB [25]. However, with this method, it does not offer us in situ information in regard to the response of the microstructure while being subjected to shearing forces, so the microstructure of CPB cannot be truly reflected. On the other hand, industrial computed tomography (CT) method has been considered as a quite hopeful technology for observation of the microstructure changes in CPB [26]. To our disappointment, this method requires that the $\mathrm{CPB}$ is kept stationary and real-time observation of the microstructure changes is not allowed. Quian et al. coupled a rheometer and FBRM to study the relationship for cement pastes with different doses of superplasticizer [27]. This provides the possibility to study the rheological and microstructural relationship of $\mathrm{CPB}$. Thus, to overcome such difficulties in investigating the microstructural and rheology response of $\mathrm{CPB}$, a method based on the coupled rheometer-FBRM to measure rheological properties and particle size was used by the authors. This method allows monitoring the size evolution and rheology changes in real time [28]. In addition, the method provides the dynamic response of the $\mathrm{CPB}$ microstructure when subjected to shearing.

\section{Materials and Methods}

\subsection{Materials}

2.1.1. Tailings. The tailings used in this study were copper ore tailings originally supplied by the Mines of Jiashi in China. It was grounded into powder below $80 \mu \mathrm{m}$ and analyzed by X-ray fluorescence (XRF) (NEX CG, Rigaku International Corp., Tokyo, Japan). Chemical characteristics of the tailings are listed in Table 1 . The tailings mainly consist of silicon dioxide, iron sesquioxide, calcium oxide, magnesium oxide, aluminum oxide, and sulphides.

The working sample particle size distribution was measured using a Topsizer 2000 Laser Particle Characterization System (Zhuhai, China), and the particle size distribution is shown in Figure 1. As shown in Figure 1, the tailings contained about $54 \mathrm{wt} . \%$ of fine particles smaller than $20 \mu \mathrm{m}, 69 \mathrm{wt} . \%$ below $37 \mu \mathrm{m}$, and $87 \mathrm{wt} . \%$ below $74 \mu \mathrm{m}$ while the specific gravity of the tailings was $2.71 \mathrm{~g} / \mathrm{cm}^{3}$.

2.1.2. Water, Binder, and Additive. A type of ordinary Portland cement (OPC) was used as the binder. The contents of the cement are shown in Table 2. According to the factory of the cement, the Blaine fineness of the cements is $402 \mathrm{~m}^{2}$ / $\mathrm{kg}$, specific gravity is 3.14 , and the initial setting time is $120 \mathrm{~min}$. A powdered polycarboxylic superplasticizer (SP) was applied to this experiment, which could promote particle dispersion and improve CPB fluidity. The deionized water was used to mix the cement and tailings.

2.2. Mixture Proportions. The CPB-A, CPA-B, CPA-C, and CPA-D were prepared at three levels of solid content, as shown in Table 3, with a constant water-to-cement (w/c) ratio of 3.0. The additive SP was added for the preparation of CPB-D at a proportion of $1 \mathrm{wt} . \%$ of the cement used as was advised by the production company of a $0.5 \mathrm{wt} . \%$ to $1.5 \mathrm{wt} . \%$ range. The mixture proportions are shown in Table 3 in $1 \mathrm{~L}$ $\mathrm{CPB}$.

2.3. Sample Preparation. In the experiment, a Hobart mixer was used for $\mathrm{CPB}$ mixtures mixing in which the velocity was under the control of the preset programs at an environment temperature of $20^{\circ} \mathrm{C}$. Four steps of mixing in the preset programs were performed for the homogenization of $\mathrm{CPB}$, as illustrated in Figure 2.

In the first stage, the mixer was turned on at a stirring speed of $140 \mathrm{rpm}$, and the tailings and half of the water were added to the mixer to stir for $30 \mathrm{~s}$. In the second stage, the cement was added and the mixer was stirred at $140 \mathrm{rpm}$ for $30 \mathrm{~s}$. In the third stage, the remaining half of the water was added and the mixer was kept at $140 \mathrm{rpm}$ for $120 \mathrm{~s}$. In the fourth stage, with the addition of SP or not (CPB-D needs to add SP, while CPA-A, CPA-B, and CPA-C not), the mixer speed was increased to $285 \mathrm{rpm}$ and the stirring was continued for $60 \mathrm{~s}$. The entire mixing time was $300 \mathrm{~s}$. After the 
TABLE 1: Chemical characteristics of the tailings.

\begin{tabular}{lccccccc}
\hline Compound & $\mathrm{SiO}_{2}$ & $\mathrm{Fe}_{2} \mathrm{O}_{3}$ & $\mathrm{CaO}$ & $\mathrm{MgO}$ & $\mathrm{Al}_{2} \mathrm{O}_{3}$ & $\mathrm{SO}_{3}$ & Rests \\
\hline Content (\%) & 50.63 & 25.54 & 9.39 & 5.39 & 2.72 & 1.92 & 4.40 \\
\hline
\end{tabular}

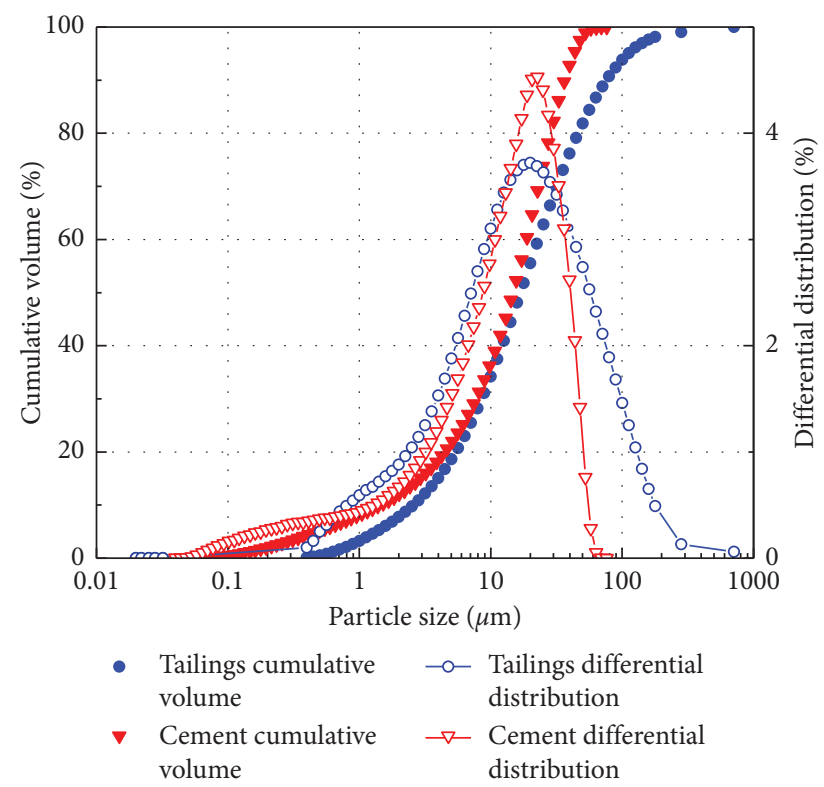

Figure 1: Particle size distribution of the unclassified tailings and cement.

TABLE 2: Contents of the cement.

\begin{tabular}{lllllllll}
\hline Items & $\mathrm{MgO}$ & $\mathrm{SiO}_{2}$ & $\mathrm{Na}_{2} \mathrm{O}$ & $\mathrm{K}_{2} \mathrm{O}$ & $\mathrm{Al}_{2} \mathrm{O}_{3}$ & $\mathrm{SO}_{3}$ & $\mathrm{Fe}_{2} \mathrm{O}_{3}$ & $\mathrm{CaO}$ \\
\hline
\end{tabular}

\begin{tabular}{lllllllll}
\hline Amount (\%) & 1.40 & 20.70 & 0.18 & 0.48 & 4.50 & 2.60 & 3.30 & 65.10
\end{tabular}

samples were prepared, each sample was transferred to the test within $30 \mathrm{~s}$.

\subsection{Experimental Methods}

2.4.1. Rheology. From a general view, the flow behavior of the non-Newtonian paste of unclassified tailings is generally represented by a simple relation between the shear stress $\tau$ and shear rate $\dot{\gamma}$, which includes a critical shear stress for the onset of flow $[29,30]$. Hence, the rheological properties of the $\mathrm{CPB}$ samples have a constitutive relationship that is generally described by the following Herschel-Bulkley flow model [31], shown in equation (1), and it was used for data fitting:

$$
\tau=\tau_{0}+K \dot{\gamma}^{n}
$$

Equation (1) represents the Herschel-Bulkley model: $\tau$ represents the shear stress, $\mathrm{Pa}$; $\tau_{0}$ represents the $\mathrm{HB}$ yield stress, $\mathrm{Pa} ; \dot{\gamma}$ represents the shear rate, $\mathrm{s}^{-1} ; n$ represents flow index; and $K$ represents the consistency index.

2.4.2. Microstructure Measure. The real-time and field particle conditions of CPB were evaluated, and the microstructure of $\mathrm{CPB}$ in fresh state was measured using a focused beam reflectivity measurement (FBRM) system (Particle Track $^{\mathrm{TM}}$ G400, Mettler Toledo, Zurich, Switzerland) [32]. Although a variety of technologies are capable of microstructure determination, few could be used to observe the sampling of suspension with low light transmittance and in situ $[33,34]$. The FBRM method is advantageous in that it could be applied in in situ observation instead of diluting or sampling from CPB [35]. The FBRM reveals particle conditions, including changes of particle counts and sizes and the chord length distributions, via measuring a number of counts of the particles and the chord length [36]. FBRM works on the principle that the probe emits a laser beam and scans the CPB particles at a rotation speed of $2 \mathrm{~m} / \mathrm{s}$, while recording the time required for each agglomeration of the laser scan [37]. The FBRM probe operation principle is shown in Figure 3. The FBRM measured thousands of chord lengths per second and obtains a chord length distribution per each measurement interval. The mean chord length of each chord length distribution is calculated as described by the following equation:

$$
\bar{C}=\frac{\sum_{i=1}^{k}\left[\left(n_{i} / \sum_{i=1}^{k} n_{i}\right) M_{i}\right]}{\sum_{i=1}^{k}\left(n_{i} / \sum_{i=1}^{k} n_{i}\right)}=\frac{\sum_{i=1}^{k} n_{i} M_{i}}{\sum_{i=1}^{k} n_{i} M_{i}^{0}}
$$

where $\bar{C}$ represents the chord length of particle, $M_{\mathrm{i}}$ represents the midpoint of an individual channel, $n_{i}$ represents the unweighted counts, and $k$ represents the upper channel number [38]. The measurement of a particle size covers a range of 0.5 to $1,000 \mu \mathrm{m}$ of the FBRM setup used in the research. FBRM experiment was performed following the manufacturer's user guide.

2.4.3. Experiment Equipment. In order to observe rheological characteristics of the CPB samples, an R/S fourpaddle rotational rheometer (Brookfield RST, Brookfield, Middleboro, America) was used in this research. During the experiment, the four-paddle rotor was immersed into the slurry, spinning at a changing shear rate. This process was under real-time monitoring, and a shear stress to shear rate curve was exported from rheometer by software for further analysis.

At the same time, in order to observe the changes in the microstructure of the paste during the rheological test, the FBRM was used. During the experiment, the rheometer and the FBRM were operated under the same computer control. The FBRM was turned on 10 seconds before the rheometers started working, and the probe began to acquire the relevant parameters of the microstructure of the paste. And during the experiment, the computer recorded every 10 seconds for the FBRM. The experimental equipment is illustrated in Figure 4 . To improve the representativeness of the test results, the probe was placed inside the sample in a direction opposite the flow at a downward angle. The probe was less than $2 \mathrm{~mm}$ from the rheometer paddle and ensured that the probe did not collide during the rheometer operation. The diameter of the probe is only $9.5 \mathrm{~mm}$, which is believed to be small enough to fail to affect the function of rheometer during the test. 
TABLE 3: Mixture proportions of CPB.

\begin{tabular}{|c|c|c|c|c|c|c|}
\hline \multirow{2}{*}{ Code } & \multirow{2}{*}{ w/c (by mass) } & \multirow{2}{*}{ vol.\% solid } & \multicolumn{4}{|c|}{ Quantity for $1 \mathrm{~L}$ paste } \\
\hline & & & SP (g) & Cement (g) & Water (g) & Tailings (g) \\
\hline CPB-A & 3.00 & 0.53 & 0 & 156.67 & 470.00 & 1301.09 \\
\hline CPB-B & 3.00 & 0.52 & 0 & 160.00 & 480.00 & 1271.11 \\
\hline CPB-C & 3.00 & 0.50 & 0 & 166.67 & 500.00 & 1211.16 \\
\hline CPB-D & 3.00 & 0.50 & 1.61 & 160.67 & 500.00 & 1211.16 \\
\hline
\end{tabular}

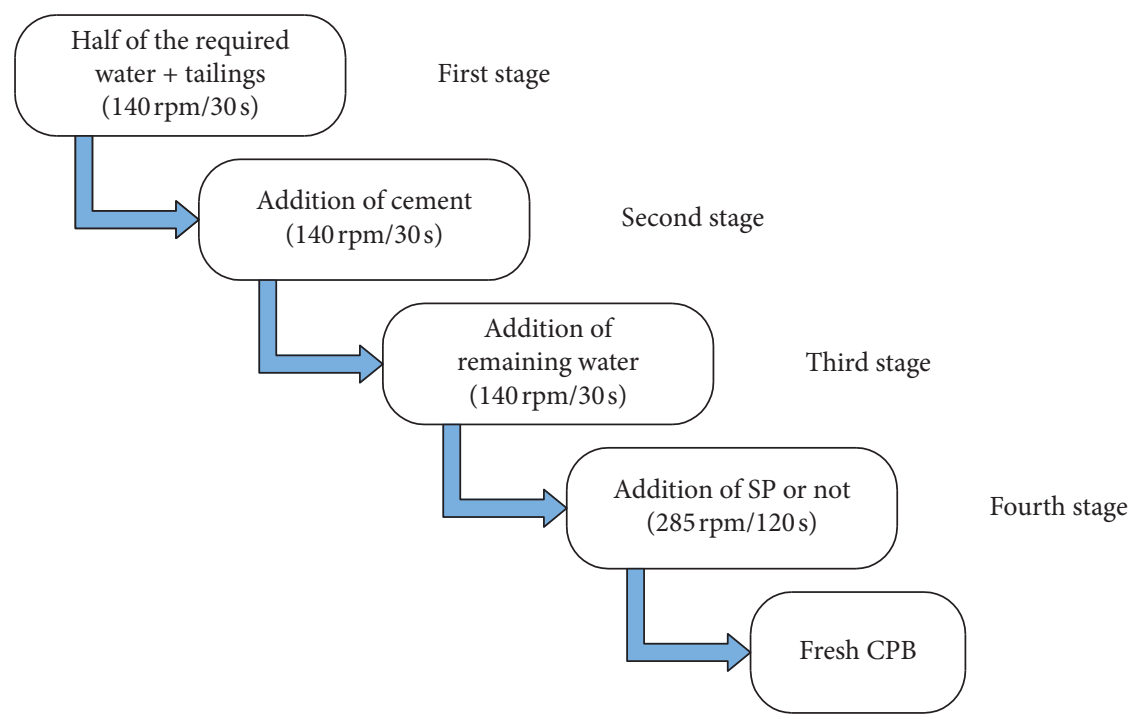

FIgURE 2: Mixing protocol to prepare CPB.

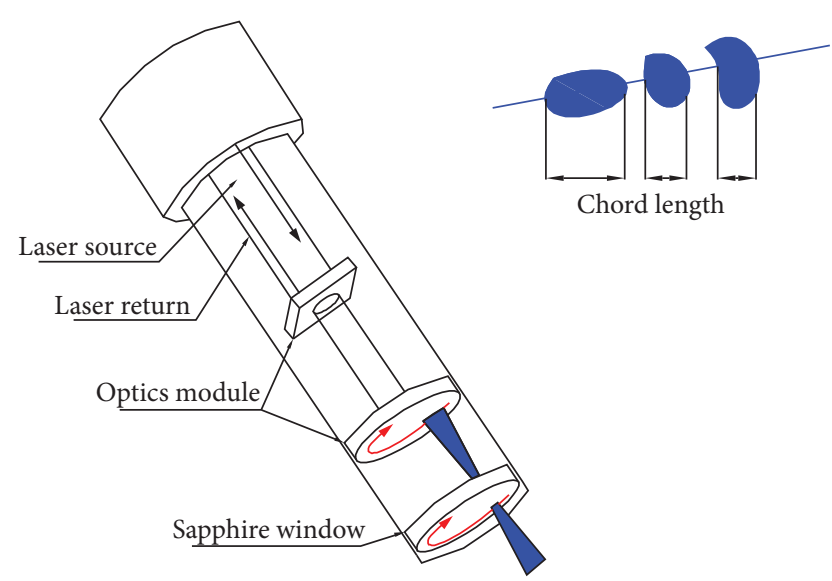

FIGURE 3: FBRM probe operation principle.

The paste was poured into the beaker, $155 \mathrm{~mm}$ in diameter and $155 \mathrm{~mm}$ in height, to a level of $90 \mathrm{~mm}$, and thereafter, the mixing rotor (VT-40-40) of the Brookfield RST and FBRM probe were immersed into the paste. The paste was under a controlled shear rate mode, and the shear rate increased continuously from 0 to $720 \mathrm{~s}^{-1}$ over $12 \mathrm{mins}$ via a step-up approach. A total of 720 points were obtained in a period of $720 \mathrm{~s}$. The beaker was placed in a water bath. The temperature of the water bath equipped on this equipment remained at $20^{\circ} \mathrm{C}$. To verify the repeatability of the test, each experiment was repeated once for each type of mixtures and the average value was calculated. A representative set of flow curves was reported to indicate the rheology or microstructure of the paste.

\section{Results and Discussion}

3.1. Rheological Properties. The relationship between shear rate and shear stress as shown in Figure 5 was drawn according to the measurements of the experiment. In order to better analyze the trend of the curves, three dashed lines were added in Figure 5, and the curves were divided into four regions: I, II, III, and IV. The division of the different regions is based on the derivative of the shear rate-shear stress curve (at the beginning of the experiment, the derivative of the curve begins to decrease and gradually approaches a stable value. When the shear rate exceeds a certain threshold, the curve derivative begins to increase). Besides, the parameters of the Herschel-Bulkley model were calculated by fitting the experimental data points of Regions I, II, and III in the figure (Region IV does not conform to the conventional rheological model and thus was not included in the fitting). The rheological behavior of CPB is presented in Table 4, and the values represented the average of two results of duplicate tests. The influence of shearing on rheological behavior of CPB is determined by many factors, such as the aggregation mechanism and mixture composition. As expected, with an increase in solid content, $\mathrm{CPB}$ samples tend to reveal a higher viscosity and yield stress, but poorer flowability. A synergistic effect of solid content and additives used appeared to control the 


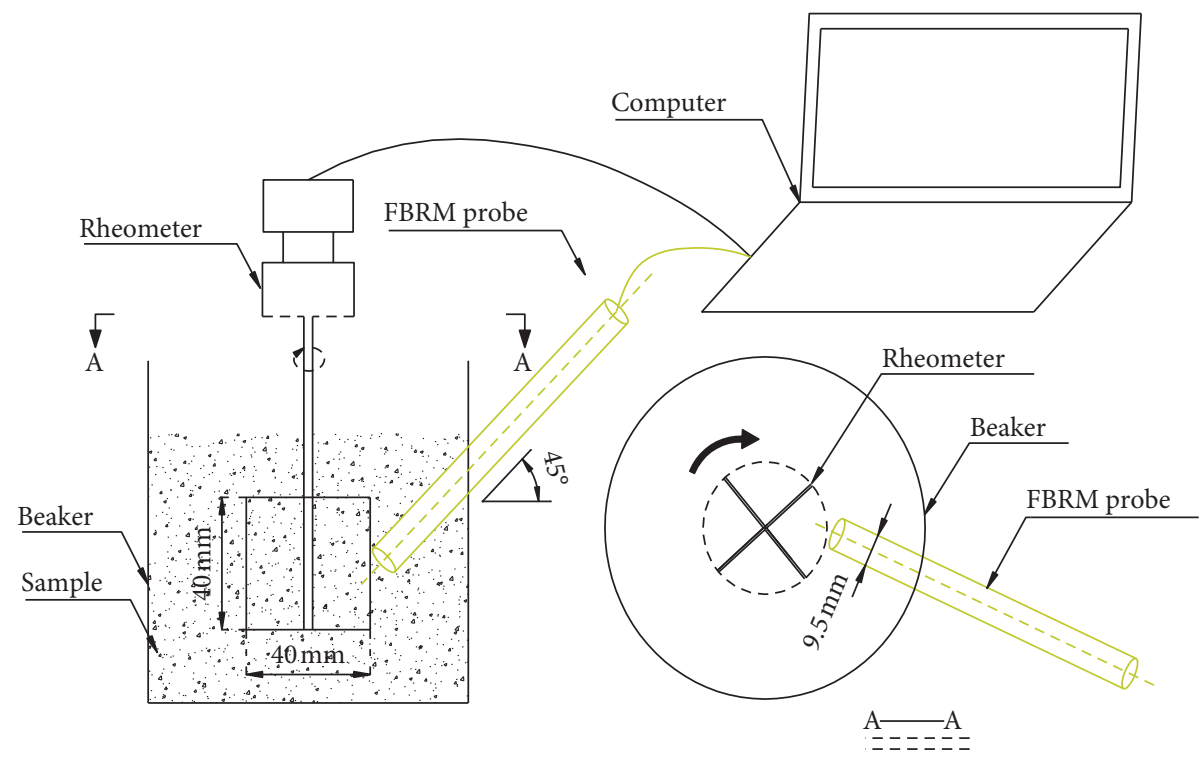

FIgURE 4: Experimental equipment.

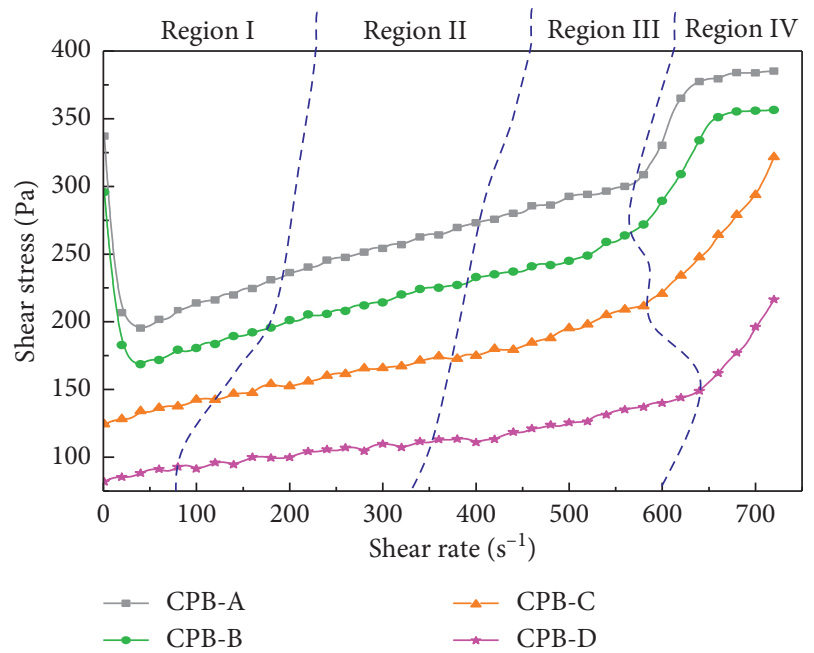

Figure 5: Influence of shear on flow curve behavior of $\mathrm{CPB}$ depending on different regions.

rheological behavior of $\mathrm{CPB}$, which has been proved in some literature [39].

As shown in Region I in Figure 5, at a relatively low shear rate range, the paste behaves as found in some literature [40], and the apparent viscosity of the paste gradually decreases as the shear rate increases, exhibiting shear thinning. The volume concentration of the paste is an important factor affecting the shear thinning characteristics, and the increase of the volume concentration enhances shear thinning. However, compared with the $\mathrm{CPB}-\mathrm{C}$ (without SP), the apparent viscosity of CPB-D (with SP) decreases slowly with the increase of shear rate (flow index of CPB-D is less than CPB-C, shown in Table 4), and the plasticizer weakens the shear thinning phenomenon. Shear thinning of the paste is believed to be related to its microstructure damage, and it may be that the plasticizer helps to keep the particles dispersed. According to the experimental fitting results in
TABLE 4: Herschel-Bulkley model parameters for CPB.

\begin{tabular}{lccccccc}
\hline \multirow{2}{*}{ Sample type } & \multirow{2}{*}{ Region } & \multicolumn{2}{c}{$K\left(\mathrm{~Pa} \cdot \mathrm{s}^{n}\right)$} & \multicolumn{2}{c}{$n(-)$} & \multicolumn{2}{c}{$R^{2}$} \\
& & $\bar{X}$ & $S$ & $\bar{X}$ & $S$ & $\bar{X}$ & $S$ \\
\hline \multirow{3}{*}{ CPB-A } & Region I & 1.510 & 0.085 & 0.70 & 0.028 & 0.98 & 0.008 \\
& Region II & 0.174 & 0.016 & 1.00 & 0.014 & 0.97 & 0.017 \\
& Region III & 0.173 & 0.003 & 1.21 & 0.042 & 0.97 & 0.028 \\
\hline \multirow{3}{*}{ CPB-B } & Region I & 1.044 & 0.078 & 0.72 & 0.021 & 0.98 & 0.004 \\
& Region II & 0.148 & 0.017 & 1.00 & 0.028 & 0.99 & 0.004 \\
& Region III & 0.148 & 0.006 & 1.17 & 0.056 & 0.98 & 0.008 \\
\hline \multirow{3}{*}{ CPB-C } & Region I & 0.566 & 0.051 & 0.76 & 0.014 & 0.99 & 0.003 \\
& Region II & 0.109 & 0.012 & 1.00 & 0.000 & 0.97 & 0.007 \\
& Region III & 0.107 & 0.007 & 1.15 & 0.056 & 0.99 & 0.003 \\
\hline \multirow{3}{*}{ CPB-D } & Region I & 0.500 & 0.038 & 0.80 & 0.029 & 0.99 & 0.001 \\
& Region II & 0.070 & 0.007 & 1.00 & 0.003 & 0.97 & 0.018 \\
& Region III & 0.071 & 0.001 & 1.12 & 0.014 & 0.96 & 0.027 \\
\hline
\end{tabular}

Note: $\bar{X}$ refers to the average of two results of duplicate tests, whereas $S$ refers to the standard deviation of two results of duplicate tests. When fitting Region I of CPB-A and CPB-B, the initial unstable data were removed.

Table 4 , the $n$ value obtained by the H-B model fitting is less than 1 , so it is considered that the paste in this stage behaves as a pseudoplastic fluid.

It is worth noting that in Region I, the initial stress values of CPB-A and CPB-B decrease rapidly with shear time, exhibiting a solid-like feature, and then begin to shift to fluid characteristics. This phenomenon is known in some literature as stress overshoot [41]. This is because the high concentration paste has a flow characteristic which is similar to a solid, and the low shear rate is not sufficient to cause the sample to flow. When the applied force first overcomes the internal structural stress, the solid-like state changes to the fluid-like state and flows, and the shear stress rapidly reduces. This phenomenon is often encountered in field cases. When the filling pump stops working for a period of time due to a fault, to restart the pump requires a larger pump pressure. 
As the shear rate further increases, the apparent viscosity of the paste converts to be a constant value, as shown in Region II of Figure 5. At this time, the shear stress of the paste increases linearly with the shear rate. According to the fitting results in Table 4 , the $n$ value obtained by the $\mathrm{H}-\mathrm{B}$ model fitting is equal to 1 , which conforms to the Bingham model, so it is considered that the paste in this stage behaves as a Bingham plastic fluid.

However, when CPB underwent a high shear rate (Region III in Figure 5), the rheological parameters (consistency index $K$ and yield stress $\tau_{0}$ ) generally increased and presented shear thickening characteristics. With the parameter fitting result (Table 4 ), it can be seen that the $n$ value obtained by fitting the H-B model is more than 1 , which is characterized by shear thickening, so it is considered that the paste at this stage behaves as a dilatant fluid. Such nonNewtonian flow behavior of the paste is believed to be caused by changes in particle distribution. Compared with Newtonian fluids, such as water, the rheological behavior of CPB is complicated under different shear rates as tiny particles are suspended in the liquid.

Notably different from the other three regions is Region IV in Figure 5. Within this range, the shear stress increases in a nearly discontinuous jump with the rising shear rate, and the rheological curve does not conform to the conventional rheological model. From this experiment, it was found that when the shear rate was more than $560 \mathrm{~s}^{-1}$, some paste far from the blade area was also rotated. In some literature, this phenomenon was called a boundary confinement, also known as the shear-blocking phenomenon $[42,43]$. It should be noted that the boundary between Region III and Region IV is not obvious. A possible speculation is that aggregations of particles eventually become big enough to stride leap the system and jam. Therefore, the phenomena of the two regions are sometimes classified into one class.

3.2. Focused Beam Reflectance Measurement. The results of the FBRM experiment, shown in Figure 6, include two aspects. One is the number of counts measured per second of particles detected in real time (Figure 6(a)), and the other is the average chord length of agglomerates or particles (Figure 6(b)). Similarly, in order to better analyze the trend of the experimental results, two dashed lines were added to divide the graph into three regions: 1,2 , and 3 . As can be seen from the figure, at a low shear rate (Region 1), the mean chord length of agglomerates or particles of CPB gradually decreased, and the number of counts measured per second of particles tended to decline. Similar to the stress overshoot phenomenon found in the rheological experiments, the average grain size of $\mathrm{CPB}-\mathrm{A}$ and $\mathrm{CPB}-\mathrm{B}$ did not decrease but increased at the beginning of shearing in the FBRM experiments. This is because that although the rheometer applies a shear stress to the sample, the stress is not sufficient to deform the sample, so that the sample remains stationary. The stationary CPB sample is affected by the interaction force of the particles, and the particles adsorb each other, resulting in a larger floc.
As expected, SP helped to disperse agglomerates, CPB-D tended to contain a larger number of fine particles (Region 1 and Region 2 in Figure 6(b)). It is in accordance with the coincident trends shown in the rheology test and is in agreement with the research of Mangane et al. [44, 45] which observed that the flowability of CPB could be improved by using plasticizer. When the shear rate gradually increased (Region 2), the microstructure of the paste reached a dynamic equilibrium, and the mean chord length and the number of counts measured per second of agglomerates or particles of $\mathrm{CPB}$ did not change significantly. However, when the shear rate further increased (around $400 \mathrm{~s}^{-1}$ in this research, homologous Region 3 in Figure 6), under the shear of the rheometer, the size of the particles in the paste did not decrease or remained the same, but it increased and the amount reduced. This means that the samples having different shear rates have different microscopic structures.

Comparing Figure 5 with Figure 6, we found some particularly interesting phenomena. In the range of Region I in Figure 5, CPB-D containing SP exhibits shear thinning under the shearing action of the rheometer. However, in Figure 6, there is no microstructural change in CPB-D (the size and number of counts measured per second of particles did not change, since SP kept CPB particles in a dispersed state) as in other samples at the corresponding shear rate in Region 1. Therefore, it can be considered that the fracture of the floc structure in the paste is a major factor causing shear thinning, but it is not the only cause. Some studies have also shown that particles that are originally disorderly distributed in viscous fluids gradually become ordered in distribution under a low shear rate, and the flow state is laminar flow, and the apparent viscosity of the paste decreases.

Another noteworthy point is that in Figure 5, Region IV exhibits an unusual jump in yield stress and apparent viscosity, but there is no significant change in the microstructure in the corresponding region in Figure 6. In many literatures, it is believed that the shear thickening of the paste is due to the shear effect that enhancing the interaction between particles, which promotes the mutual adsorption of the particles and results in a rapid increase in the apparent viscosity and yield stress of the paste $[46,47]$. However, the results of this experiment showed that this view was not completely correct. The mutual aggregation between the particles is a factor in the shear thickening of the paste, but it is not the main factor, and the boundary confinement is the main reason for the jump growth of shear stress and viscosity.

\subsection{The Relationship between Rheology and Microstructure of} $C P B$. The non-Newtonian flow behavior of suspensions such as $\mathrm{CPB}$ is thought to be caused by changes in particle placements under different shear rates. From the above rheological and microstructure experiments, we could conduct a more in-depth study of this problem. The particlescale experiment revealed that the suspension rheology characteristics were due to the interaction of particles. It is generally believed that shear thinning is caused by the attraction between particles, steric (solid particle) repulsion, 


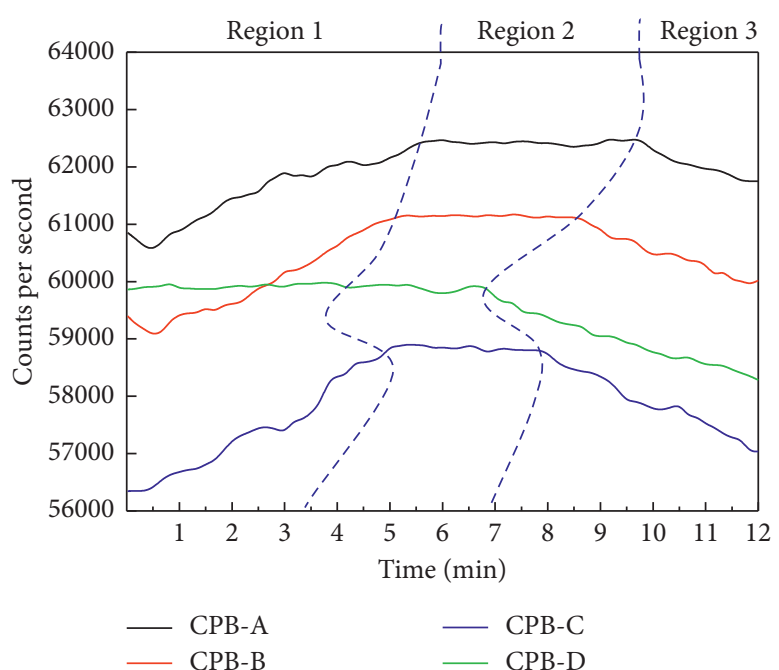

(a)

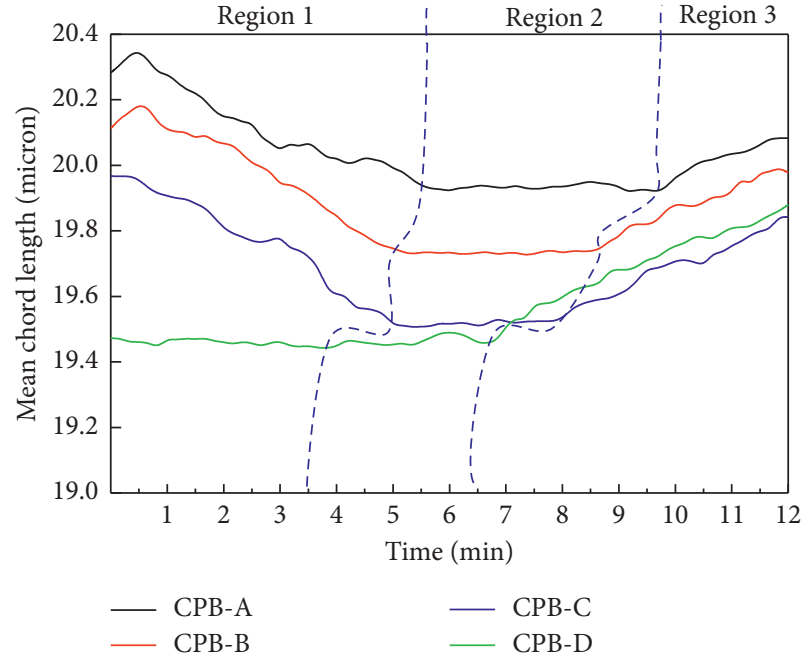

(b)

FIGURE 6: Influence of shear on microstructural of CPB depending on different regions.

and electrostatic potential, and these forces can lead to a microstructure that is either loose interconnection or random [48]. The sketch of shear thinning and shear thickening for $\mathrm{CPB}$ suspensions is shown in Figure 7, and the microstructure evolution of $\mathrm{CPB}$ gives an explanation to the transitions to shear thinning and shear thickening. With an increase in the shear rate, random collisions among particles become organized in the flow, lowering the viscosity. When the external shearing and the force between the particles are balanced, the apparent viscosity of the particles will no longer change, and the paste exhibits Bingham fluid properties.

However, the rheological parameters do not always decrease or be constant with the increase of shear rate. On the contrary, when the shear rate exceeds a certain threshold value, the rheological parameters change as a result of shear thickening. Research has shown that the chemical and physical qualities of the suspension system changed once the shear rate differed $[49,50]$. The intense shear of CPB promoted the aggregation (red, in Figure 7) of particles. The formation of agglomerates is not only due to hydration but also due to interparticle forces produced from the colloidal state of the finest cement grains [51]. Han and Ferron have said that this is related to the shrinking electric layer of a particle, which increases the interaction between particles [52].

As the distance between particles decreases, the interaction force between particles is mainly affected by the electric double layer (EDL) thickness. As is known to all, the ionic concentration is the key factor affecting the thickness of EDL [53, 54], and the thickness could be represented by the Debye-Hückel length equation (equation (3)) [55]:

$$
\frac{1}{\kappa}=\sqrt{\frac{\varepsilon \varepsilon_{0} R T}{2 F^{2} I}}
$$

where $1 / \kappa$ is the thickness of EDL, $\varepsilon_{0}$ is the permittivity of the vacuum, $I$ is the ionic strength, $\varepsilon$ is the dielectric constant (relative permittivity) of the dispersion medium, $R$ is the gas constant, $T$ is the absolute temperature, and $F$ is the Faraday constant. A higher ionic concentration will result in decreasing of the thickness of EDL, leading to stronger/increased agglomeration (they stick together) [56], forming aggregation called hydroclusters [57]. In the shear thickening regime of $\mathrm{CPB}$, the viscous drag-mediated reciprocities involving hydroclusters lead to a relatively slight increase in viscosity, usually no more than $50 \%$.

On the other hand, particles in a strong flow are difficult to flow around each other, leading to a larger rate of energy dissipation and a surge in shear stress and viscosity. This is due to the dense particle arrangements that begin to swell and squeeze the boundary under shearing resulting in frictional particle contacts between the particles. Therefore, strong shear thickening can be attributed to the introduction of a new stress scale, in this case of the stiffness of the boundary. There is no inevitable connection between hydroclusters and boundary constraints in this experiment, which requires more research to explore.

Therefore, the variation among shear thinning, Bingham behavior, and shear thickening are regarded to be related to the evolution of particle arrangements. It needs to be specially pointed out that whether shear thinning belongs to a kind of thixotropic phenomenon is not the goal of this study (this kind of phenomenon is reversible). Instead, it can be confirmed that shear thickening of CPB is related to the shrinking of the electric double layer and boundary confinement, which is an irreversible change, so a possible speculation is that the shear thickening in this research may not be a thixotropic phenomenon. This hypothesis remains to be directly proven by more experiments in further researches, for instance, ion concentrations measurements of the pore solution chemistry of $\mathrm{CPB}$. In some literature, researchers believed that both shear thinning and shear thickening belonged to the scope of thixotropy of CPB. The authors herein think that 


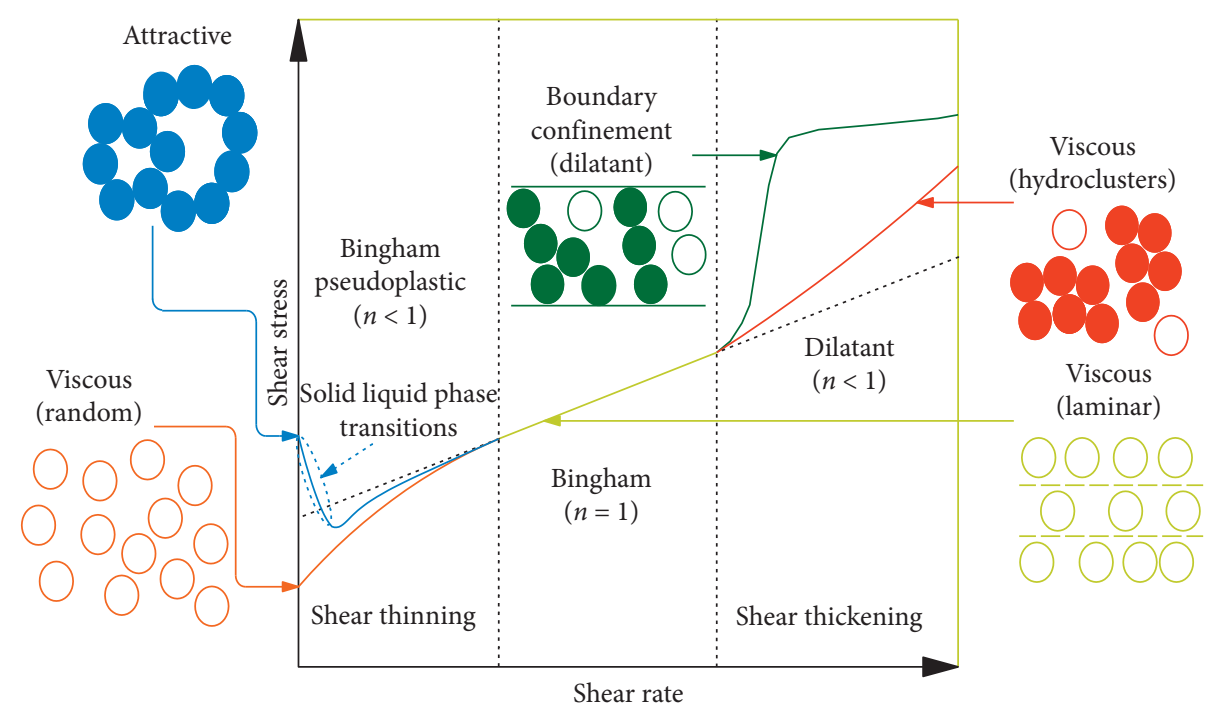

FIGURE 7: Change in the microstructure of $\mathrm{CPB}$ explains the transition to shear thinning and shear thickening.

this is a controversial point of view, and the microstructural difference between the two performances should be further studied to verify the viewpoint.

\section{Conclusion}

The rheological properties and microstructure of cemented paste backfill were evaluated using the coupled rheometerFBRM. The results of this study contribute to better understanding of the mechanism of how rheological behavior affects CPB due to changes in the shear rate. The evolution of particle arrangement of a paste is the key to explaining the complex rheological behavior. The changes in the microstructure of the sample must be fully considered when studying the rheological behavior of CPB.

$\mathrm{CPB}$, as a particular concentrated suspension, may present several kinds of rheological behavior, depending on material properties and the shear rate. With an increase in shear rate (the shear rate around $100 \mathrm{~s}^{-1}$ in this research), the loose interconnection of particles is destroyed or random collisions among particles come to be organized in the flow, lowering the viscosity (shear thinning).

Higher shear rates (around $400 \mathrm{~s}^{-1}$ in this research) promote the aggregation of particles, forming aggregation called hydroclusters. The average chord length of agglomerates or particles in the sample increases with time, and the hydroclusters could lead to a relatively mild increase in the viscosity of CPB (shear thickening) which is usually no more than $50 \%$. On the other hand, boundary confinement leads to a larger rate of energy dissipation and a surge in shear stress and viscosity. This phenomenon requires more research to determine whether there is a link between boundary constraints and hydroclusters.

\section{Data Availability}

The data used to support the findings of this study are available from the corresponding author upon request.

\section{Conflicts of Interest}

The authors declare that there are no conflicts of interest regarding the publication of this paper.

\section{Acknowledgments}

This work received financial support from the National Key Technologies R\&D Program for the 13th Five-Year Plan (2017YFC0602903) as well as the National Natural Science Foundation of China (51374304).

\section{References}

[1] X. Deng, J. Zhang, B. Klein, N. Zhou, and B. deWit, "Experimental characterization of the influence of solid components on the rheological and mechanical properties of cemented paste backfill," International Journal of Mineral Processing, vol. 168, pp. 116-125, 2017.

[2] S. Ouellet, B. Bussière, M. Mbonimpa, M. Benzaazoua, and M. Aubertin, "Reactivity and mineralogical evolution of an underground mine sulphidic cemented paste backfill," Minerals Engineering, vol. 19, no. 5, pp. 407-419, 2006.

[3] R. Sharam and T. AL-busaidi, "Groundwater pollution due to a tailings dam," Engineering Geology, vol. 60, no. 1, pp. 235244, 2001.

[4] W.-d. Jiang, "Fractal character of lenticles and its influence on sediment state in tailings dam," Journal of Central South University of Technology, vol. 12, no. 6, pp. 753-756, 2005.

[5] J.-f. Zha, G.-l. Guo, W.-k. Feng, and Q. Wang, "Mining subsidence control by solid backfilling under buildings," Transactions of Nonferrous Metals Society of China, vol. 21, no. S3, pp. s670-s674, 2011.

[6] W.-B. Guo, Q.-L. Hou, Y.-F. Zou, Y. Liu, and Q. Wang, "Relationship between surface subsidence factor and mining depth of strip pillar mining," Transactions of Nonferrous Metals Society of China, vol. 21, no. S3, pp. s594-s598, 2011.

[7] T. Belem and M. Benzaazoua, "Design and application of underground mine paste backfill technology," Geotechnical and Geological Engineering, vol. 26, no. 2, pp. 147-174, 2008. 
[8] Q.-L. Zhang and X.-M. Wang, "Performance of cemented coal gangue backfill," Journal of Central South University of Technology, vol. 14, no. 2, pp. 216-219, 2007.

[9] M. Fall, J. Célestin, M. Pokharel, and M. Touré, “A contribution to understanding the effect of temperatures on the mechanical properties of mine cemented tailings backfill: experimental results," Engineering Geology, vol. 114, no. 3-4, pp. 397-413, 2010.

[10] A.-X. Wu, Z.-E. Ruan, Y.-M. Wang et al., "Simulation of longdistance pipeline transportation properties of whole-tailings paste with high sliming," Journal of Central South University, vol. 25, no. 1, pp. 141-150, 2018.

[11] Y. Wang, M. Fall, and A. Wu, "Initial temperature-dependence of strength development and self-desiccation in cemented paste backfill that contains sodium silicate," Cement and Concrete Composites, vol. 67, pp. 101-110, 2016.

[12] M. Fall, M. Benzaazoua, and S. Ouellet, "Experimental characterization of the influence of tailings fineness and density on the quality of cemented paste backfill," Minerals Engineering, vol. 18, no. 1, pp. 41-44, 2005.

[13] S. Dragana and G. Merray, "Apparent yield stress measurement in cemented paste backfill," International Journal of Surface Mining Reclamation \& Environment, vol. 27, no. 4, pp. 231-256, 2013.

[14] H. Jiang and M. Fall, "Yield stress and strength of saline cemented tailings in sub-zero environments: Portland cement paste backfill," International Journal of Mineral Processing, vol. 160, no. 5, pp. 68-75, 2017.

[15] D. Wu and S.-J. Cai, "Coupled effect of cement hydration and temperature on hydraulic behavior of cemented tailings backfill," Journal of Central South University, vol. 22, no. 5, pp. 1956-1964, 2015.

[16] L. Yang, H. Wang, A. Wu, P. Xing, and W. Gao, “Thixotropy of unclassified pastes in the process of stirring and shearing," Journal of University of Science and Technology Beijing, vol. 38, no. 10, pp. 1343-1349, 2016.

[17] C. Liang and M. Fall, "An evolutive elasto-plastic model for cemented paste backfill," Computers and Geotechnics, vol. 71, pp. 19-29, 2016.

[18] R. D. Ferron, S. Shah, E. Fuente, and C. Negro, "Aggregation and breakage kinetics of fresh cement paste," Cement and Concrete Research, vol. 50, pp. 1-10, 2013.

[19] R. Larson, The Structure and Rheology of Complex Fluids, Oxford University Press, New York, NY, USA, 1999.

[20] B. O'Sullivan and B. Glennon, "Application of in situ FBRM and ATR-FTIR to the monitoring of the polymorphic transformation of d-mannitol," Organic Process Research and Development, vol. 9, no. 6, pp. 884-889, 2015.

[21] H. K. Lee, K. M. Lee, Y. H. Kim, H. Yim, and D. B. Bae, "Ultrasonic in-situ monitoring of setting process of highperformance concrete," Cement and Concrete Research, vol. 34, no. 4, pp. 631-640, 2004.

[22] F. Jiangang, C. Kaida, W. Hui, G. Chao, and L. Wei, "Recovering molybdenite from ultrafine waste tailings by oil agglomerate flotation," Minerals Engineering, vol. 39, no. 6, pp. 133-139, 2012.

[23] S. Panchal, D. Deb, and T. Sreenivas, "Variability in rheology of cemented paste backfill with hydration age, binder and superplasticizer dosages," Advanced Powder Technology, vol. 29, no. 9, pp. 2211-2220, 2018.

[24] A. Ritchie, The Rheology of Fresh Concrete, Pitman Books Limited, Boston, MA, USA, 1983.

[25] C. Liu, B. Shi, J. Zhou, and C. Tang, "Quantification and characterization of microporosity by image processing, geometric measurement and statistical methods: application on SEM images of clay materials," Applied Clay Science, vol. 54, no. 1, pp. 97-106, 2011.

[26] P. Trtik, A. Diaz, M. Guizar-Sicairos, A. Menzel, and O. Bunk, "Density mapping of hardened cement paste using ptychographic X-ray computed tomography," Cement and Concrete Composites, vol. 36, pp. 71-77, 2013.

[27] Y. Qian, K. Lesage, K. El Cheikh, and G. De Schutter, "Effect of polycarboxylate ether superplasticizer (PCE) on dynamic yield stress, thixotropy and flocculation state of fresh cement pastes in consideration of the critical micelle concentration (CMC)," Cement and Concrete Research, vol. 107, pp. 75-84, 2018.

[28] K. Michel, J. Eggers, and M. Mazzotti, "Measurement of particle size and shape by FBRM and in situ microscopy," Chemical Engineering Science, vol. 63, no. 19, pp. 4656-4675, 2008.

[29] D. Wu, M. Fall, and S. J. Cai, "Coupling temperature, cement hydration and rheological behaviour of fresh cemented paste backfill," Minerals Engineering, vol. 42, no. 2, pp. 76-87, 2013.

[30] X. J. Deng, B. Klein, D. J. Hallbom, B. de Wit, and J. X. Zhang, "Influence of particle size on the basic and time-dependent rheological behaviors of cemented paste backfill," Journal of Materials Engineering and Performance, vol. 27, no. 7, pp. 3478-3487, 2018.

[31] J. Haiqiang, M. Fall, and L. Cui, "Yield stress of cemented paste backfill in sub-zero environments: experimental results," Minerals Engineering, vol. 92, pp. 141-150, 2016.

[32] A. Blanco, C. Negro, J. Tijero, and E. Fuente, "Flocculation monitoring: focused beam reflectance measurement as a measurement tool," Canadian Journal of Chemical Engineering, vol. 80, no. 4, pp. 1-7, 2002.

[33] P. Barrett and B. Glennon, "In-line FBRM monitoring of particle size in dilute agitated suspensions," Particle \& Particle Systems Characterization, vol. 16, no. 5, pp. 207-211, 1999.

[34] X. Hu, J. Cunningham, and D. Winstead, "Study growth kinetics in fluidized bed granulation with at-line FBRM," International Journal of Pharmaceutics, vol. 347, no. 1-2, pp. 54-61, 2008.

[35] A. R. Heath, P. D. Fawell, P. A. Bahri, and J. D. Swift, "Estimating average particle size by focused beam reflectance measurement (FBRM)," Particle \& Particle Systems Characterization, vol. 19, no. 2, pp. 84-95, 2002.

[36] R. Irizarry, A. Chen, R. Crawford, L. Codan, and J. Schoell, "Data-driven model and model paradigm to predict $1 \mathrm{D}$ and 2D particle size distribution from measured chord-length distribution," Chemical Engineering Science, vol. 164, pp. 202-218, 2017.

[37] D. Han and R. D. Ferron, "Effect of mixing method on microstructure and rheology of cement paste," Construction and Building Materials, vol. 93, pp. 278-288, 2015.

[38] M. Arellano, H. Benkhelifa, D. Flick, and G. Alvarez, "Online ice crystal size measurements during sorbet freezing by means of the focused beam reflectance measurement (FBRM) technology. Influence of operating conditions," Journal of Food Engineering, vol. 113, no. 2, pp. 351-359, 2012.

[39] L. Liu, K. Song, D. Lao, and T. Kwon, "Rheological properties of cemented tailing backfill and the construction of a prediction model," Materials, vol. 8, no. 5, pp. 2076-2092, 2015.

[40] F. Toussaint, C. Roy, and P.-H. Jézéquel, "Reducing shear thickening of cement-based suspensions," Rheologica Acta, vol. 48, no. 8, pp. 883-895, 2009.

[41] A. Aerov and M. Krüger, "Theory of rheology in confinement," Physical Review E, vol. 92, no. 4, article 042301, 2015. 
[42] X. Qiao, X. Zhang, Y. Tian, and Y. Meng, "Modeling the response of a quartz crystal microbalance under nanoscale confinement and slip boundary conditions," Physical Chemistry Chemical Physics, vol. 17, no. 11, pp. 7224-7231, 2015.

[43] M. B. C. Mangane, R. Argane, R. Trauchessec, A. Lecomte, and M. Benzaazoua, "Influence of superplasticizers on mechanical properties and workability of cemented paste backfill," Minerals Engineering, vol. 116, pp. 3-14, 2018.

[44] L. Huynh, D. A. Beattie, D. Fornasiero, and J. Ralston, "Effect of polyphosphate and naphthalene sulfonate formaldehyde condensate on the rheological properties of dewatered tailings and cemented paste backfill," Minerals Engineering, vol. 19, no. 1, pp. 28-36, 2006.

[45] A. Kate and N. Wagner, "Microstructure and rheology relationships for shear thickening colloidal dispersions," Journal of Fluid Mechanics, vol. 769, pp. 242-276, 2015.

[46] A. G. Chryss, S. N. Bhattacharya, and L. Pullum, "Rheology of shear thickening suspensions and the effects of wall slip in torsional flow," Rheologica Acta, vol. 45, no. 2, pp. 124-131, 2005.

[47] N. J. Wagner and J. F. Brady, "Shear thickening in colloidal dispersions," Physics Today, vol. 62, no. 10, pp. 27-32, 2009.

[48] M. Cyr, C. Legrand, and M. Mouret, "Study of the shear thickening effect of superplasticizers on the rheological behaviour of cement pastes containing or not mineral additives," Cement and Concrete Research, vol. 30, no. 9, pp. 1477-1483, 2000.

[49] D. Lootens, P. Hébraud, E. Lécolier, and H. Van Damme, "Gelation, shear-thinning and shear-thickening in cement slurries," Oil \& Gas Science and Technology, vol. 59, no. 1, pp. 31-40, 2004.

[50] K. Rdem, K. Khayat, and A. Yahia, "Correlating rheology of self-consolidating concrete to corresponding concreteequivalent mortar," ACI Materials Journal, vol. 106, no. 2, pp. 154-160, 2010.

[51] D. Han and R. D. Ferron, "Influence of high mixing intensity on rheology, hydration, and microstructure of fresh state cement paste," Cement and Concrete Research, vol. 84, pp. 95-106, 2016.

[52] R. Hunter, Foundations of Colloid Science, Oxford University Press, New York, NY, USA, 2001.

[53] T. Cosgrove, Colloid Science: Principles, Methods and Applications, Blackwell Publishing, Hoboken, NJ, USA, 2005.

[54] M. Yang, C. Neubauer, and H. Jennings, "Interparticle potential and sedimentation behaviour of cement suspensions review and results from paste," Advanced Cement Based Materials, vol. 5, no. 1, pp. 1-7, 1997.

[55] R. Ferron, Formwork pressure of self-consolidating concrete: influence of flocculation mechanisms, structural rebuilding, thixotropy and rheology, Ph.D. thesis, Northwestern University, Evanston, IL, USA, 2008.

[56] M. C. Newstein, H. Wang, N. P. Balsara et al., "Microstructural changes in a colloidal liquid in the shear thinning and shear thickening regimes," Journal of Chemical Physics, vol. 111, no. 10, pp. 4827-4838, 1999.

[57] H. Cheng, Characteristics of rheological parameters and pipe resistance under the time-temperature effect, Ph.D. thesis, University of Science and Technology Beijing, Beijing, China, 2018. 


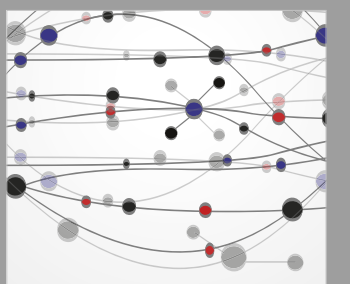

The Scientific World Journal
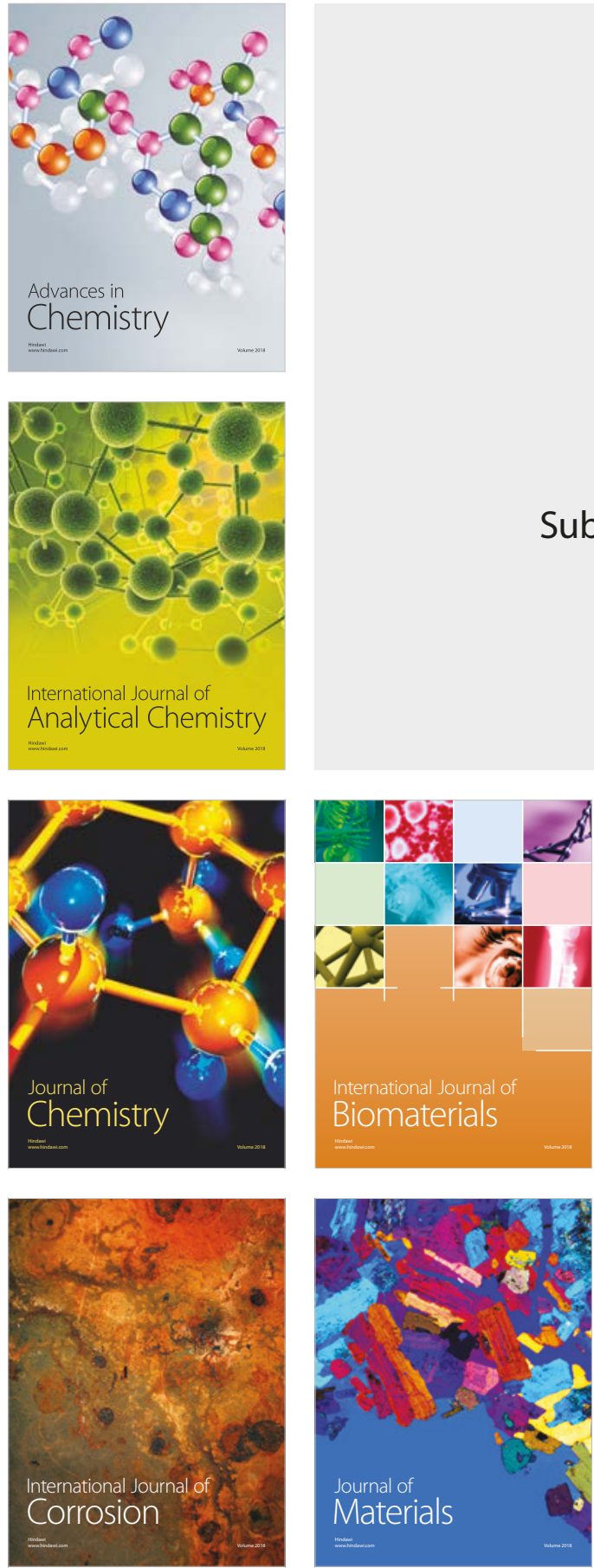

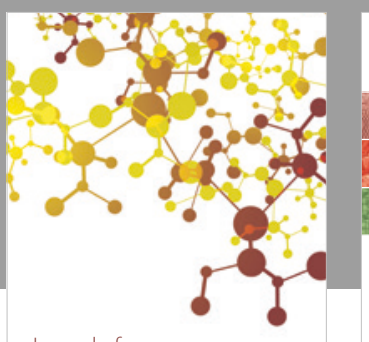

Journal of

Applied Chemistry
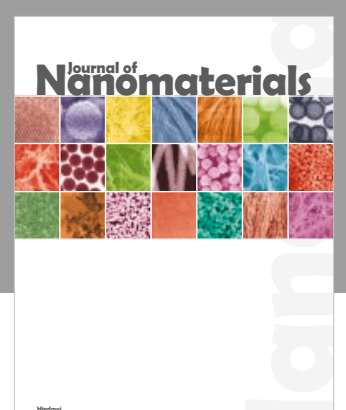

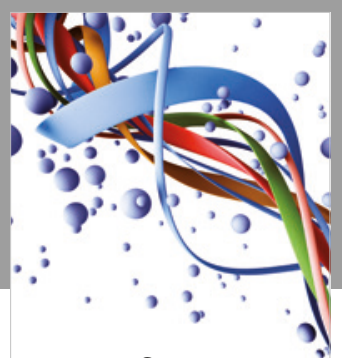

Scientifica

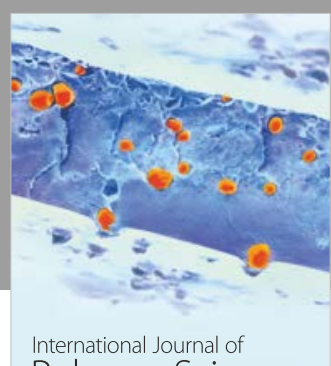

Polymer Science

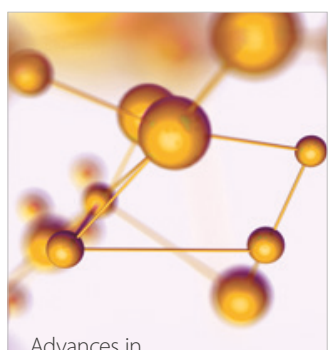

Physical Chemistry
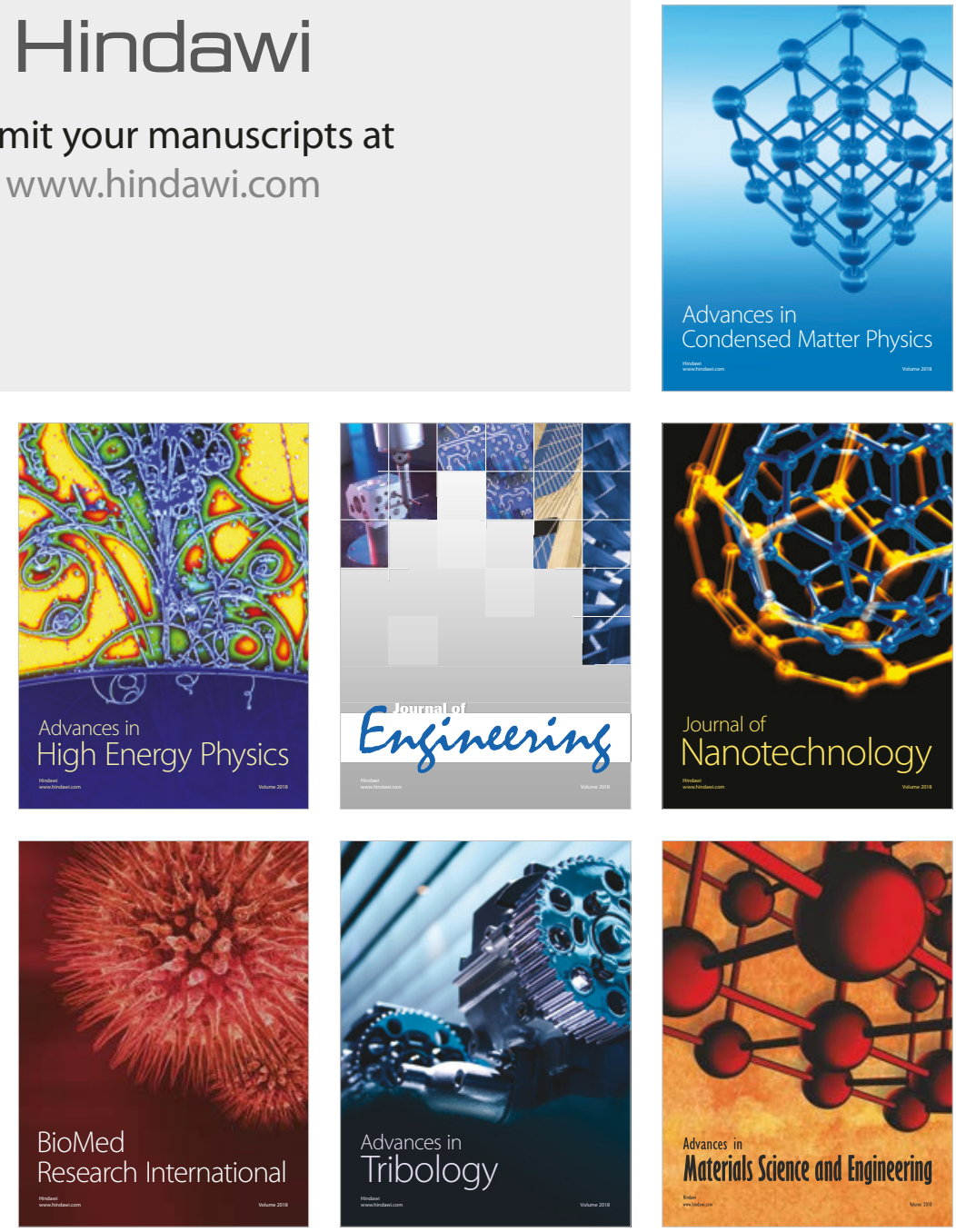